CONTRACTOR REPORT

SAND95-2182

Unlimited Release

UC-814

Yucca Mountain Site Characterization Project

\title{
Frictional Sliding in Layered Rock: Laboratory-Scale Experiments
}

B. J. Buescher, Jr., K. E. Perry, Jr., and J. S. Epstein Idaho National Engineering Laboratory

Idaho Falls, Idaho

Prepared by

Sandia National Laboratories

Albuquerque, New Mexico 87185 and Livermore, Califomia 94550

for the United States Department of Energy

under Contract DE-AC04-94AL85000

Approved for public release; distribution is unlimited.

Printed September 1996 
"Prepared by Yucca Mountain Site Characterization Project (YMSCP) participants as part of the Civilian Radioactive Waste Management Program (CRWM). The YMSCP is managed by the Yucca Mountain Project Office of the U.S. Department of Energy, DOE Field Office, Nevada (DOE/NV). YMSCP work is sponsored by the Office of Geologic Repositories (OGR) of the DOE Office of Civilian Radioactive Waste Management (OCRWM)."

Issued by Sandia National Laboratories, operated for the United States Department of Energy by Sandia Corporation.

NOTICE: This report was prepared as an account of work sponsored by an agency of the United States Government. Neither the United States Government nor any. agency thereof, nor any of their employees, nor any of their contractors, subcontractors, or their employees, makes any warranty, express or implied, or assumes any legal liability or responsibility for the accuracy, completeness, or usefulness of any information, apparatus, product, or process disclosed, or represents that its use would not infringe privately owned rights. Reference herein to any specific commercial product, process, or service by trade name, trademark, manufacturer, or otherwise, does not necessarily constitute or imply its endorsement, recommendation, or favoring by the United States Government, any agency thereof or any of their contractors or subcontractors. The views and opinions expressed herein do not necessarily state or reflect those of the United States Government, any agency thereof or any of their contractors.

Printed in the United States of America. This report has been reproduced directly from the best available copy.

Available to DOE and DOE contractors from

Office of Scientific and Technical Information

PO Box 62

Oak Ridge, TN 37831

Prices available from (615) 576-8401, FTS 626-8401

Available to the public from

National Technical Information Service

US Department of Commerce

5285 Port Royal Rd

Springfield, VA 22161

NTIS price codes

Printed copy: A03

Microfiche copy: A01 
SAND95-2182

Distribution

Unlimited Release

Category UC-814

Printed September 1996

\title{
Frictional Sliding in Layered Rock: Laboratory-Scale Experiments
}

\author{
B. J. Buescher, Jr., K. E. Perry, Jr. and J. S. Epstein \\ Idaho National Engineering Laboratory \\ Idaho Falls, Idaho
}

\begin{abstract}
Understanding the mechanical behavior of jointed-rock masses is of critical importance to designing and predicting the performance of a nuclear waste repository. To this end we have studied the frictional sliding between simulated rock joints using phase shifting moiré interferometry. A model was constructed from a stack of granite plates that were machined and sand-blasted to provide a uniform frictional interface. Load was applied monotonically and phase shifted moire fringe patterns were recorded at different load states. Plots of slip along the interfaces for the model are presented and demonstrate the ability of the photomechanics technique to provide precise measurement of frictional slip along the rock interfaces.
\end{abstract}


This work was conducted at the Idaho National Engineering Laboratory on behalf of Sandia National Laboratories. The work was conducted for the U.S. Department of Energy under contract number DE-AC04-94AL85000. This work activity was directed and planned using Work Agreement WA-0190, Revision 00 and Sandia contract AJ-8906 for work description WBS Number 1.2.3.2.7.4 for the Yucca Mountain Site Characterization Office. This work activity was performed under the controls of a qualified QA program. The experimental data used in this report may be found under Data Tracking Number SNL02040792001.002. 


\section{DISCLAIMER}

Portions of this document may be illegible in electronic image products. Images are produced from the best available original document. 


\section{DISCLAIMER}

This report was prepared as an account of work sponsored by an agency of the United States Government. Neither the United States Government nor any agency thereof, nor any of their employees, makes any warranty, express or implied, or assumes any legal liability or responsibility for the accuracy, completeness, or usefulness of any information, apparatus, product, or process disclosed, or represents that its use would not infringe privately owned rights. Reference herein to any specific commercial product, process, or service by trade name, trademark, manufac. turer, or otherwise does not necessarily constitute or imply its endorsement, recommendation, or favoring by the United States Government or any agency thereof. The views and opinions of authors expressed herein do not necessarily state or reflect those of the United States Government or any agency thereof. 


\subsection{Introduction}

The work described in this report performed at the Idaho National Engineering laboratory is part of the rock mechanics effort at Sandia National Laboratories for the Yucca Mountain Site Characterization Program. The laboratory-scale experiments conducted for this work are intended to provide high quality data on the mechanical behavior of jointed structures that can be used to validate complex numerical models for rock-mass behavior. Given the difficulty in obtaining the quality and quantity of data necessary for code validation efforts from field experiments, this work provides calibrated data for the numerical modeling activities.

Frictional sliding between simulated rock joints was studied in the laboratory using the technique of phase shifting moire interferometry. A model was constructed from stacks of granite plates that had been machined and sandblasted to provide a uniform frictional surface. The model contained a central hole bored normal to the plane of the plates, so that frictional slip would be induced between the plates near the hole under external compressive loading.

The design of the granite specimen was guided by preliminary experiments performed by Brown [1] and by Perry et al. [2]. Brown [1] measured slip in a layered stack of polycarbonate plates with a central circular hole under unixial loading using geometric moiré techniques. Perry et al. [2] performed similar experiments using phase-shifting moiré interferometry. Figure 1 details the overall design of the rock model used in the current experiment, which was similar to the polycarbonate models used in the previous two sets of experiments. Differences in specimen design between these three sets of experiments are discussed later.

A 300 line/mm diffraction grating was replicated on the front surface of the model and interrogated with the INEL's phase shifting moire interferometer. During monotonic loading of the models, fringe patterns representing the in-plane surface displacements were recorded at several loads. The relative slip between the plates was determined from these fringe patterns as a function of position along the interfaces.

Moire interferometry [3] is a high-sensitivity method of full-field displacement measurement. The technique directly provides contour maps of the two orthogonal in-plane displacement components, $u$ and $v$.

Phase shifting [4,5] is an efficient means of converting the grayscale fringe pattern information from moiré interferograms into a digital representation of optical phase. The smoothing provided by the data reduction algorithm is performed in time (over several discrete phase shifts), not in space, so a degree of noise reduction is obtained without loss of spatial detail. This is important when specimens contain edges and discontinuities.

The outputs of the technique are two-dimensional surface maps of in-plane displacement. Phase shifting moiré interferometry offers an experimental counterpart to the powerful computational methods of solid mechanics, where displacements and strains are also the primary output.[6]. 
The measurements using the phase shifting moiré interferometer have a precision on the order of 1.67 microns with a spatial resolution determined by the amount of magnification chosen in the imaging system. In the experiments performed, the viewing width was $38.4 \mathrm{~mm}$ which yields a spatial resolution of $06 \mathrm{~mm}$. This is based on a disaggregation of the image by the video imaging system to $640 \times 240$ (line-doubled to $640 \times 480$ to simplify calculations) pixels and 256 gray levels. Because the smoothing provided by phase shifting does not distort the detail near edges and discontinuities, the information right up to the edge of the interfaces can be used to determine relative slip between plates.

The experimental details concerning the fabrication of the model, the load frame and fixture, and the data acquisition procedures are summarized below. Finally, results for two experiments are presented in the form of plots of slip versus position along two interfaces around the hole.

\subsection{Experimental Details}

\subsection{Model Design}

The differences in specimen design between the three sets of experiments (the experiment described in the current report and those described in references [1] and [2] respectively) are primarily in the relative dimensions of the model. Perry increased the length of the model from that used by Brown to one foot, which was eight times the diameter of the hole. In this report the specimen geometry was changed once more to facilitate construction of the model since granite was only readily available in 10 " $\times 10$ " plates $3 / 8$ " thick. The original models had been made with $1 / 4$ " thick plates of Lexan. The height of the model was kept the same so $1 / 3$ fewer plates were used, which changed the geometry of the joints at the hole (which was also kept the same size). Also, the ends of the granite model were left free (the ends of the Lexan models were fixed for convenience in construction and handling) to more closely match the numerical modeling efforts at Sandia.

\subsection{Model Construction}

The model was constructed from 16 plates, 2 " wide by 10 " long, of $3 / 8$ " thick Cold Springs Black Granite purchased from Idaho Travertine. Further information on the material is given below, under the heading "Material and Interfacial Properties". After cutting and squaring, both sides of the plates were machined flat to within $1 / 1000$ " with a diamond-tipped bit and sand-blasted to ensure uniform surface roughness. The plates were then clamped together and one face machined flat. A 1.5" diameter hole was bored through the center with a diamond core drill. The model was then disassembled and finished as follows:

1. The plates were cleaned with soap and water.

2. The frictional surfaces of the middle plates (those onto which a grating was to be replicated) were carefully covered with plastic adhesive tape to protect them from epoxy seeping between $\mathrm{n}$ the plates during the grating replication process.

3. The front surface of the model was carefully aligned with a precision granite surface. The model was then clamped together with C-clamps and a pair of metal plates to distribute the load from the clamps. 
4. A 300 line/mm aluminized photoplate diffraction grating was replicated on the front surface of the model using Micro-Measurements PC-6 epoxy.

5. The plates were then separated so that the tape could be removed. The edges of the gratings were gently polished with fine (600 grit) sandpaper to remove any "overlap" that could interfere with the sliding of the plates or damage the grating.

6. The adhesive tape was carefully removed from the frictional surfaces of the plates. Any remaining adhesive was painstakingly removed with xylene.

7. The model was reassembled and the plates realigned optically.

\subsection{Material and Interfacial Properties}

The wave velocities for the granite were measured at room-dry conditions and found to be 6.2 $\mathrm{mm} / \mu \mathrm{s}$ for compression and $3.63 \mathrm{~mm} / \mu \mathrm{s}$ for shear. The density of the material is $2.96 \mathrm{~g} / \mathrm{cm}^{3}$, resulting in the following dynamically-derived elastic properties: Young's modulus, E =96.7 GPa, Shear Modulus, $\mathrm{G}=39.0 \mathrm{GPa}$, Poisson's ratio, $v=.24$. Specimen moisture was not measured as the porosity of the granite is negligible. The manufacturer of the granite plates, the Cold Spring Granite Company, provided the following material properties:

Absorption by weight: $0.112 \%$ (via ASTM test method C97)

Density: $2870.51 \mathrm{~kg} / \mathrm{m}^{3}$. (via ASTM test method C97)

Compressive strength: $134.48 \mathrm{MPa}$ (via ASTM test method C170)

Flexural strength: 12.23 MPa (via ASTM test method C880)

The static coefficient of friction $\mu_{\mathrm{s}}$ for the granite was measured between two of the plates of the model with an ASTM standard incline test (G115) to be 0.46 . The report by Brown [1] contains more information regarding the experimental procedures used to determine the ultrasonic data.

\subsection{Load Frame and Fixture}

A compact load frame designed for use on an optical table and constructed for this work by Perry et al. [2] was used. Gear boxes were chosen to provide sufficient mechanical advantage to allow the frame to be operated by hand. This avoided potential vibration problems from an electric or hydraulic drive. Further details of the frame construction are given in [2].

A loading fixture was used that consisted of two 2" $\times 2$ " x 12 " steel bars. An addition 2" $\times 2$ " $\times 6$ " length of steel bar was used in conjunction with a pair of dowel pins to ensure even distribution of load to the specimen. The fixture and the model are shown schematically in Figure 1.

\subsection{Application of Moire to the Rock Model Experiment}

There were several issues associated with the application of moire interferometry to this problem that were initially addressed in the construction of the Lexan model [2]. The specimen construction and grating replication method were tailored from this experience to allow the grating to be replicated onto each of the plates separately without introducing large rotations across the discontinuity of the interfaces between the plates.

An additional issue was the existence of discontinuities (the frictional surfaces) between the plates themselves. Typically, only one continuous diffraction grating is interrogated during a moiré 


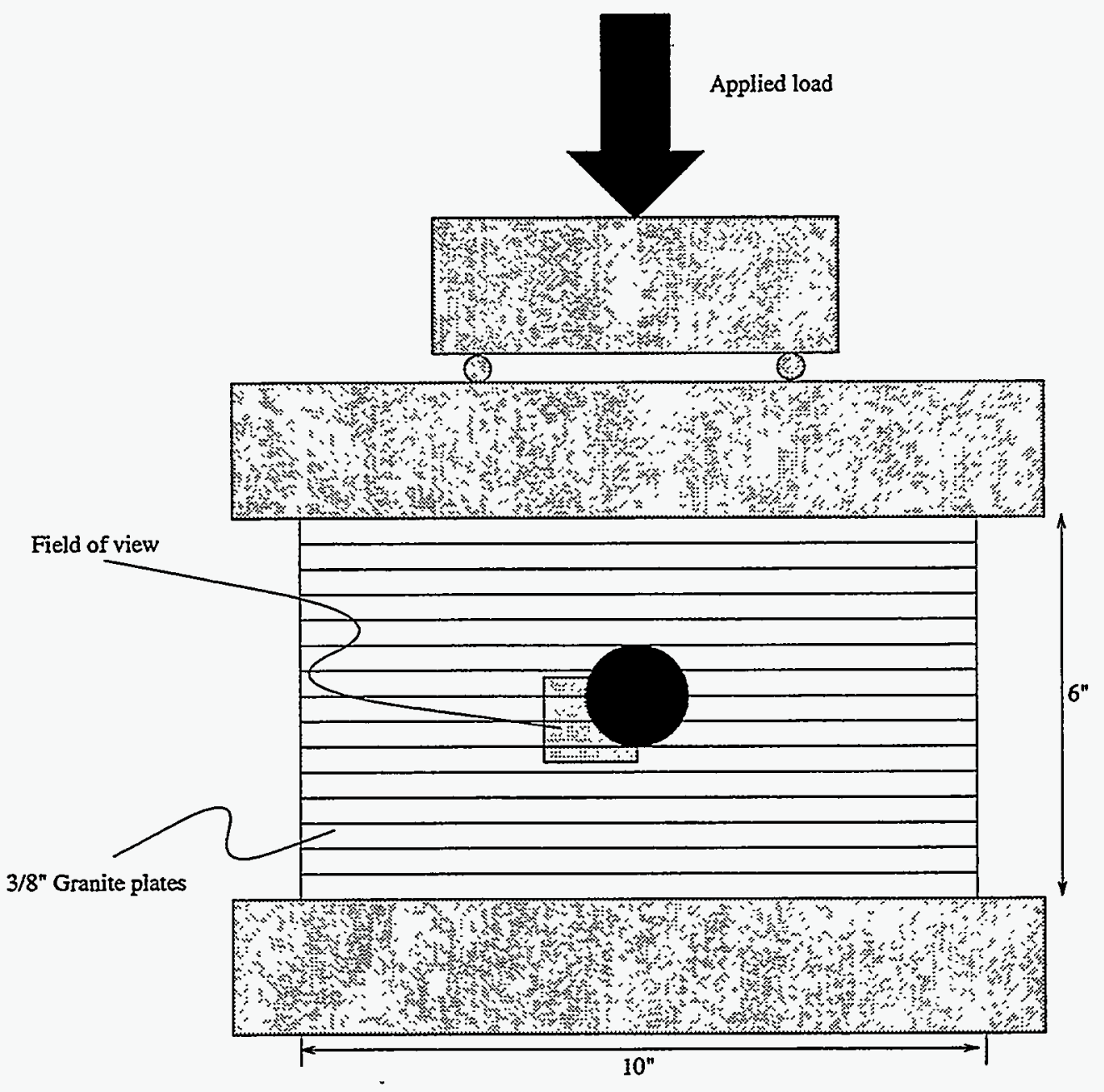

Figure 1: Rock model and load fixture. 


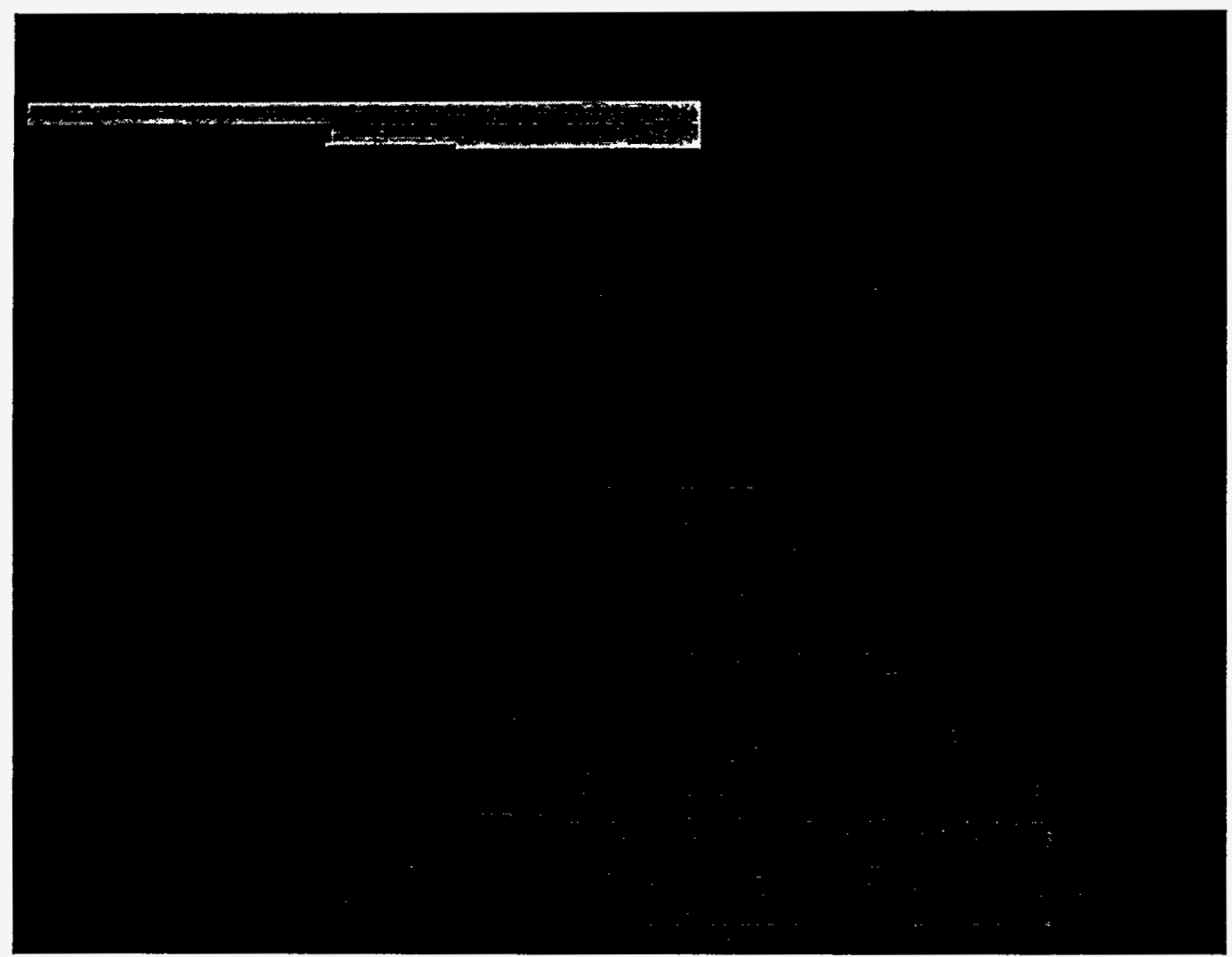

Figure 2: Typical unwrapped fringe pattern of the model in Figure 1 


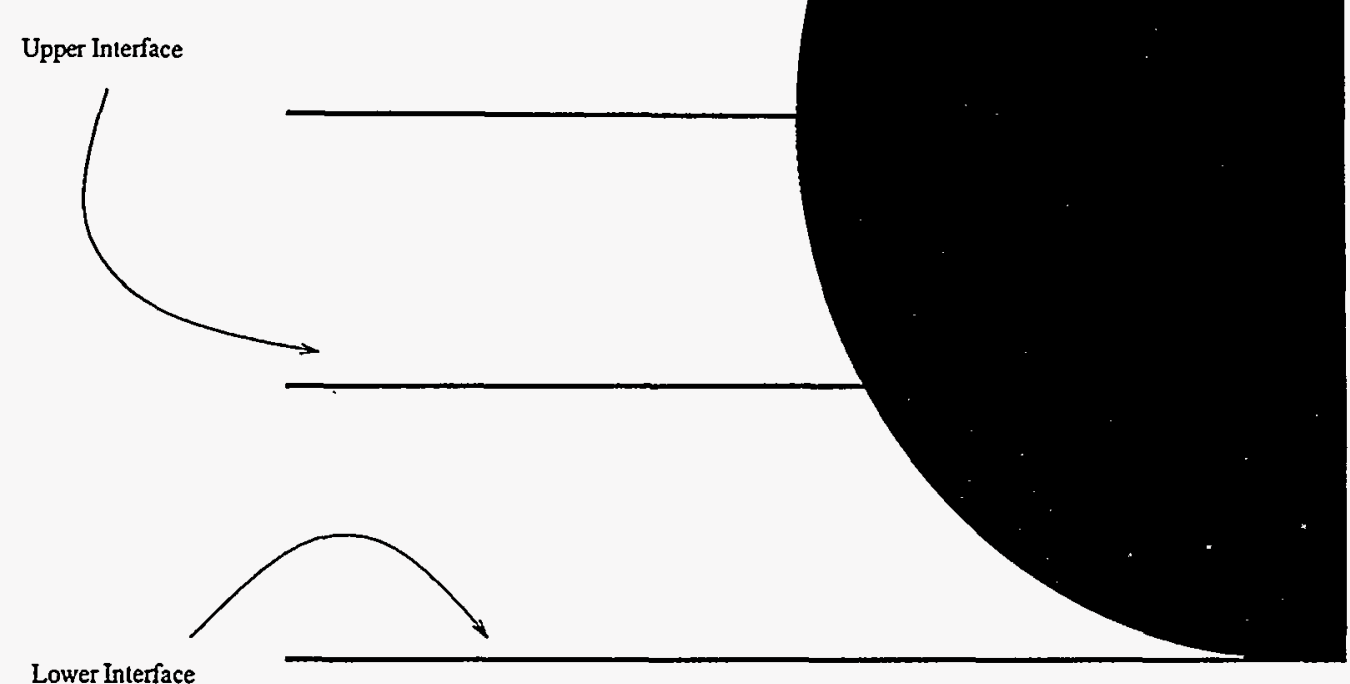

Figure 3: Close-up of the imaged region of the model in Figure 1. 
interferometry experiment. In this work, however, the area of interest was covered with separate gratings (one per plate), each one rotated slightly relative to its neighbors. This introduced different initial carrier patterns for each of the plates. This made the usual technique of minimizing these patterns to one fringe or less and accepting displacement data to be valid to within a constant unworkable. Fringe patterns at a minimal preload (null patterns) were therefore captured and used as a reference so that absolute displacement measurements could be made. The phase-shifting technique allows zero load or initial null patterns to be directly subtracted from subsequent loaded fringe patterns.

\subsection{Description of the Interferometer System}

The INEL's four beam fiber optic interferometer was used for this work [2]. This interferometer combines two separate two beam interferometers to provide both horizontal (u) and vertical (v) components of displacement. Central to the system is a four-way fiber optic beam splitter assembly that converts a single uncollimated beam of Argon-ion laser light into four equal intensity beams channeled through individual fibers. More detail about the interferometer, including a schematic illustrating the fiber optic assembly is given in reference [2].

Four $50 \mathrm{~mm}$ diameter camera lenses are located at the end of the fibers and are used to collimate the laser light from the individual fiber sources. The four lenses are mounted on an aluminum bar frame in pairs--- two lenses are mounted in a vertical plane, the other two lenses are mounted in a horizontal plane. The entire frame can be rotated to remove any relative rotational misalignment between the interferometer and the specimen.

At any one time, one pair of lenses is capped so that only two lenses project light onto the specimen surface. For example, the vertical pair of lenses can be capped so that the horizontal pair of lenses can be used alone to form fringe patterns representing the in-plane horizontal displacements. The angle between the two beams incident on the specimen grating is chosen so that both beams are diffracted onto a path normal to the surface of the specimen. When these two beams are recombined using a conventional optical system (lens and camera), they interfere with each other and form a fringe pattern.

Phase shifting is accomplished by stretching one of the selected fibers using a piezoelectric (PZT) transducer. This transducer is under the control of the laboratory workstation so that the phase shifting can be synchronized with the video image acquisition.

Wrapped fringe patterns are obtained by acquiring five images with 90 degree phase shifts between the images. These images are then preprocessed with a simple algorithm to produce the wrapped fringe pattern, which is saved for postprocessing. The wrapped fringe patterns are unwrapped during postprocessing using a recursive flood-fill algorithm. The xi fringe analysis software package from Renegade Solutions was licensed for this application and for extracting quantitative data from these unwrapped fringe patterns.

\subsection{Experimental Results}

The model was subjected to three consecutive tests. Each test consisted of unloading the model 
completely, aligning the optics, and taking null patterns at a nominal pre-load. The load would then be increased gradually, and fringe patterns acquired at predetermined load states. The data acquisition software provides the preprocessing necessary to condense the set of phase stepped images for a given load state into one wrapped fringe pattern. The image must then be masked to remove areas with questionable phase data and to mark discontinuities such as the frictional interfaces in this experiment, and the phase unwrapped. After this, the unwrapped null pattern was subtracted from each deformed fringe pattern to provide a measure of absolute displacement.

The unwrapped fringe patterns can be useful in that they provide a qualitative representation of full-field data. A good example is shown in the report by Perry et al. [2] using Lexan. However, in these experiments with granite, the level of slip was small and any qualitative interpretation by inspection of pseudocolor images of the fringe patterns would be dubious. Figure 2 shows an example of an unwrapped fringe pattern from these tests in grayscale. To obtain a quantitative measure of slip as a function of position along the interface, line scans of displacement were extracted above and below the interface and subtracted from each other. Figure 3 depicts a closeup of Figure 1 in the area where the grating was replicated. The two interfaces from which data were extracted are labeled as "upper" and "lower". Figures 4a-c and 5a-c show slip as a function of position for two interfaces at several load states, with positive slip indicating that the upper plate slipped towards the hole relative to the lower place. It should be noted that the data is not smoothed in any way as compared to the Lexan data described in [2]. This was done because of the large grain size (several $\mathrm{mm}$ ) of the granite used which introduces significant local fluctuations in surface properties and thus in the measured frictional slip. It should also be noted that zero displacement was arbitrarily chosen at the hole end of each interface to facilitate comparison to the results for the Lexan model in [2].

\subsection{Conclusions}

The graphs in figure sets 4 and 5 show a clear evolution of slip with increasing load. Since the rock was not cycled through several iterations of loading and unloading to prevent potential damage to the model, the quantitative differences between the three data sets depicted are probably due to a "wearing-in" effect. This evidences the stochastic nature of frictional interfaces in rock. Nevertheless, all the graphs show good resolution of local detail. By examining some of the flatter regions of the graphs the level of sinusoidal systematic noise in the interferometer can be seen to be significantly smaller than some of the strong local fluctuations. In fact, initial attempts to smooth the data introduced anomalous results due to artifacts of polynomial fitting, and would have made it impossible to normalize the data in any consistent fashion. However, in the unsmoothed data, much interesting detail is evident. Of particular interest is the very clear pinning in Figure $4 \mathrm{a}$ at about $-25 \mathrm{~mm}$ from the hole. In subsequent tests (Figures $4 \mathrm{~b}$ and $4 \mathrm{c}$ ) on the upper interface there are also several areas (see the region from about $-5 \mathrm{~mm}$ to $-15 \mathrm{~mm}$ on figure $4 \mathrm{~b}$ ) that initially lock up and then release at higher loads. Along the lower interface, evolution of slip is more uniform, in essential agreement with the Lexan results [2]. Still, the highly variable spatial frequency of the data--- which can be distinguished from noise by its amplitude--- is evident. Again, this is probably due to the large grain size of the granite and the stochastic frictional processes. An unusual feature of the evolution of slip with increasing load, which is also present in the data from the Lexan model experiments by Perry [2], is that as the load gets larger, some plates seem to return to a null position. It is not clear why this should occur. 


\subsection{Future Work}

A model with vertical cuts ("blocky rock") has been fabricated for further testing. It will be loaded in an inclined loading arrangement in the existing load frame. A linear bearing system has been constructed and is available for interrogating larger areas of the model surfaces. Moiré interferometry can also be used to calibrate digital image correlation, which is of interest because of its potential for use in the field for examining deformations and slip in geologic scale layered rock structures. Further examination of the current data for correlation of the "jagginess", or variability in spatial frequency, of the data to the typical grain size of the granite would also be of potential interest.

\subsection{References}

[1] Stephen R. Brown. Laboratory measurements of frictional slip on interfaces in a polycarbonate rock mass model. SAND Report SAND93-2365, Geomechanics Department, Sandia National Laboratories, Albuquerque, New Mexico, 1993. (NNA.940315.0001)

[2] K.E. Perry, Jr., B.J. Buescher, D. Anderson, and J.S. Epstein. Frictional Sliding in Layered Rock Model: Preliminary Experiments. SAND Report SAND94-2384, Sandia National Laboratories, Albuquerque, New Mexico, 1995.

[3] D. Post, B. Han, and P. Ifju. High Sensitivity Moiré. Springer-Verlag, 1994.

(MOL.19950329.0263)

[4] K.E. Perry, Jr. Calculation of energy release rates for delaminations in composite materials. Ph.D. thesis, University of Strathclyde, November 1993.

[5] J.E. Greivenkamp and J.H. Bruning. Phase Shifting Interferometry. In Daniel Malacara, editor, Optical Shop Testing, chapter 14, pages 501-598. John Wiley \& Sons, New York, 1986. Series in Pure and Applied Optics. (MOL.19950307.0004)

[6] D. Post. Moiré Interferometry. In A.S. Kobyashi, editor, Handbook on Experimental Mechanics, chapter 7, pages 314-383. Prentice-Hall, Inc., 1987. Society of Experimental Mechanics.

(MOL.19950414.0263) 

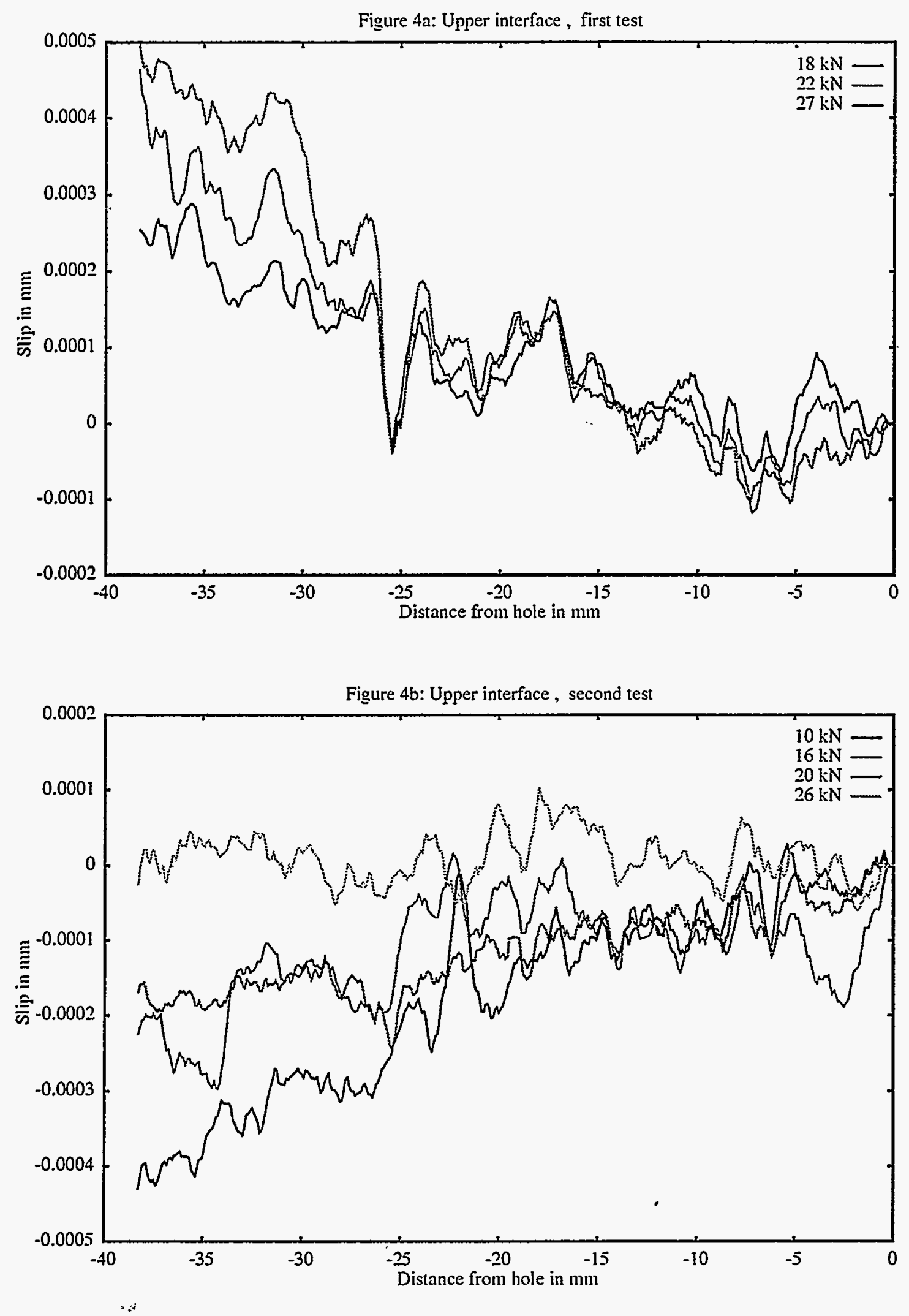

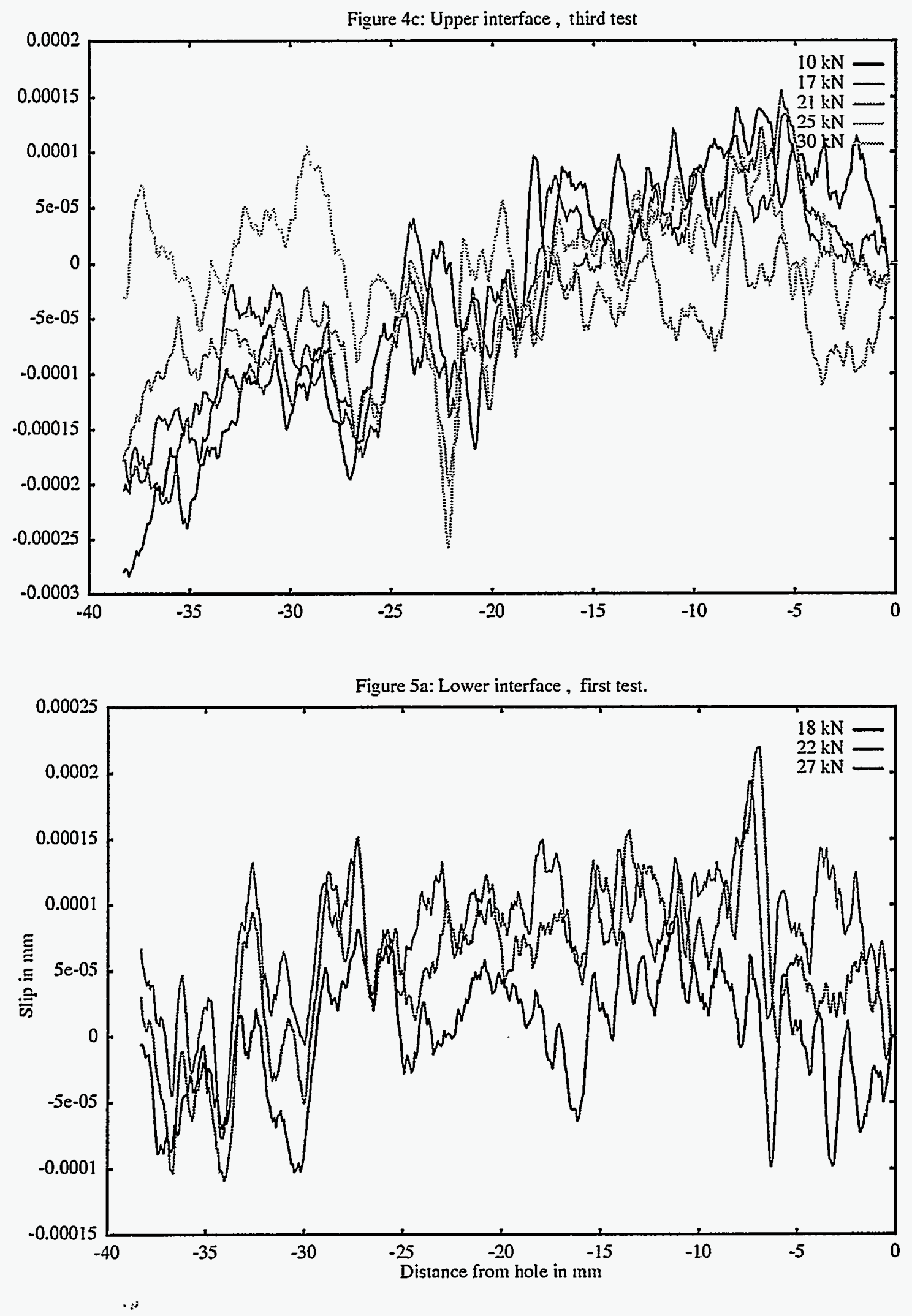

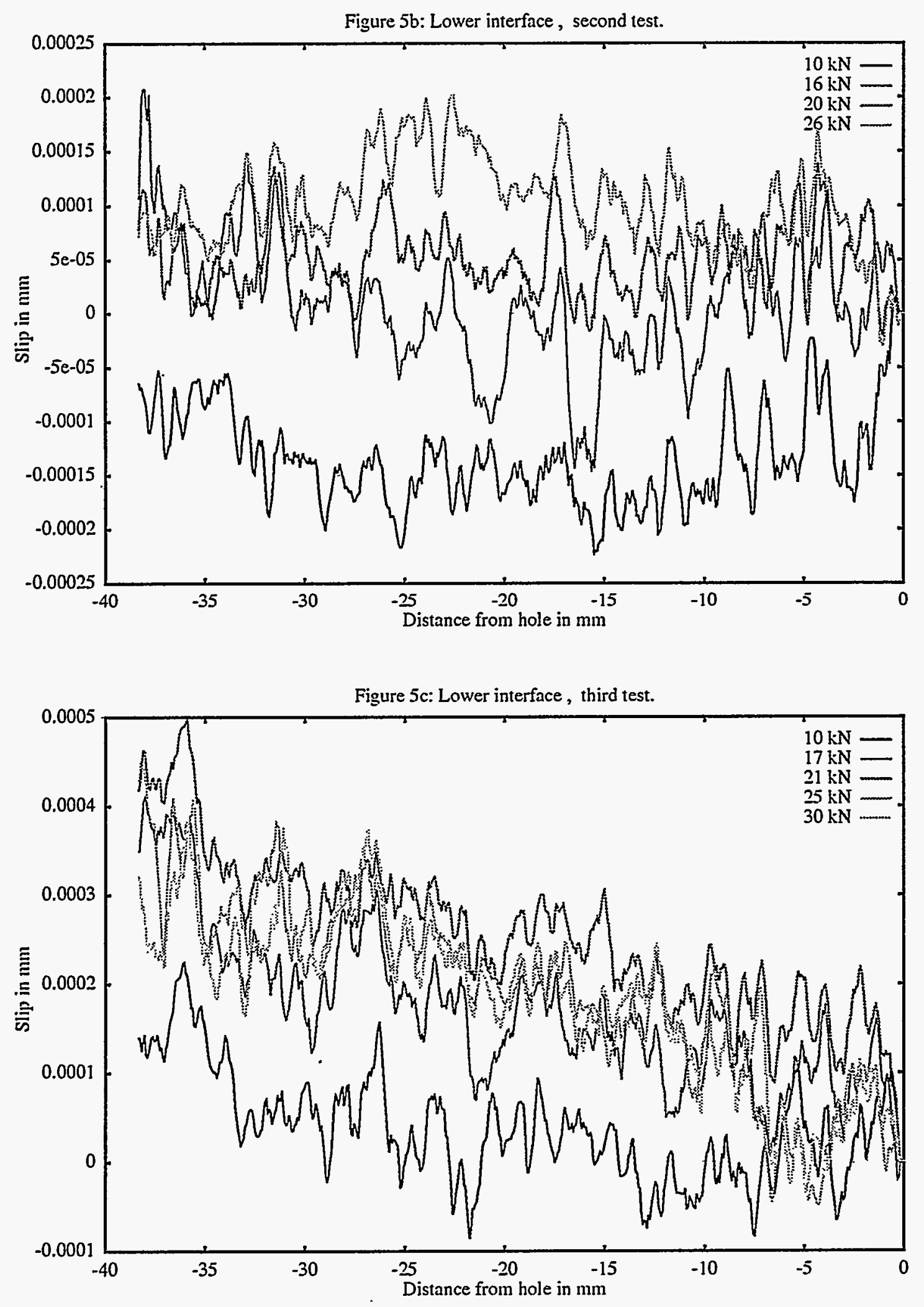


\section{YUCCA MOUNTAIN SITE CHARACTERIZATION PROJECT \\ SAND95-2182- DISTRIBUTION LIST}

9/12/96

1

D. A. Dreyfus (RW-1)

Director

OCRWM

US Department of Energy

1000 Independence Avenue SW

Washington, DC 20585

$1 \quad$ L. H. Barrett (RW-2)

Acting Deputy Director

OCRWM

US Department of Energy

1000 Independence Avenue SW

Washington, DC 20585

1 S. Rousso (RW-40)

Office of Storage and Transportation

OCRWM

US Department of Energy

1000 Independence Avenue SW

Washington, DC 20585

1 R. A. Milner (RW-30)

Office of Program Management

and Integration

OCRWM

US Department of Energy

1000 Independence Avenue SW

Washington, DC 20585

1 D. R. Elle, Director

Environmental Protection Division

DOE Nevada Field Office

US Department of Energy

P.O. Box 98518

Las Vegas, NV 89193-8518

$1 \quad$ T. Wood (RW-14)

- Contract Management Division

OCRWM

US Department of Energy

1000 Independence Avenue SW

Washington, DC 20585

4 Victoria F. Reich, Librarian

Nuclear Waste Technical Review Board 1100 Wilson Blvd., Suite 910

Arlington, VA 22209

1 Wesley Barnes, Project Manager

Yucca Mountain Site Characterization

Office

US Department of Energy

P.O. Box 98608-MS 523

Las Vegas, NV 89193-8608
1 Director, Public Affairs Office

c/o Technical Information Resource Center

DOE Nevada Operations Office

US Department of Energy

P.O. Box 98518

Las Vegas, NV 89193-8518

8 Technical Information Officer

DOE Nevada Operations Office

US Department of Energy

P.O. Box 98518

Las Vegas, NV 89193-8518

1 J. R. Dyer, Deputy Project Manager

Yucca Mountain Site Characterization Office

US Department of Energy

P.O. Box 98608 - MS 523

Las Vegas, NV 89193-88608

$1 \quad$ M. C. Brady

Laboratory Lead for YMP

M\&O/Sandia National Laboratories

1261 Town Center Drive

Bldg. 4, Room 421A

Las Vegas, NV 89134

1 J. A. Canepa

Laboratory Lead for YMP

EES-13, Mail Stop J521

M\&O/Los Alamos National Laboratory

P.O. Box 1663

Los Alamos, NM 87545

1 Repository Licensing \& Quality

Assurance

Project Directorate

Division of Waste Management, MS T7J-9

US NRC

Washington, DC 20555

1 Senior Project Manager for Yucca

Mountain

Repository Project Branch

Division of Waste Management, MS T7J-9

US NRC

Washington, DC 20555

$1 \quad$ NRC Document Control Desk

Division of Waste Management, MS T7J-9

US NRC

Washington, DC 20555 
NRC Site Representative

301 E Stewart Avenue, Room 203

Las Vegas, NV 89101

1 Center for Nuclear Waste

Regulatory Analyses

Southwest Research Institute

6220 Culebra Road

Drawer 28510

San Antonio, TX 78284

2

W. L. Clarke

Laboratory Lead for YMP

$\mathrm{M} \& \mathrm{O} /$ Lawrence Livermore Nat'l Lab

P.O. Box 808 (L-51)

Livermore, CA 94550

1 Robert W. Craig

Acting Technical Project Officer/YMP

US Geological Survey

101 Convention Center Drive, Suite P-110

Las Vegas, NV 89109

1 J. S. Stuckless, Chief

Geologic Studies Program

MS 425

Yucca Mountain Project Branch

US Geological Survey

P.O. Box 25046

Denver, CO 80225

$1 \quad$ L. D. Foust

Technical Project Officer for YMP

TRW Environmental Safety Systems

101 Convention Center Drive

Suite P-110

Las Vegas, NV 89109

1 A. L. Flint

U. S. Geological Survey

MS 721

P. O. Box 327

Mercury, NV 89023

1 Robert L. Strickler

Vice President \& General Manager

TRW Environmental Safety Systems, Inc.

2650 Park Tower Dr.

Vienna, VA 22180

1 Jim Krulik, Geology Manager

US Bureau of Reclamation

Code D-8322

P.O. Box 25007

Denver, CO 80225-0007
1

B. T. Brady

Records Specialist

US Geological Survey

MS 421

P.O. Box 25046

Denver, CO 80225

$1 \quad$ M. D. Voegele

Deputy of Technical Operations

M\&O/SAIC

101 Convention Center Drive

Suite P-110

Las Vegas, NV 89109

2 A. T. Tamura

Science and Technology Division

OSTI

US Department of Energy

P.O. Box 62

Oak Ridge, TN 37831

1 P. J. Weeden, Acting Director

Nuclear Radiation Assessment Div. US EPA

Environmental Monitoring Sys. Lab

P.O. Box 93478

Las Vegas, NV 89193-3478

1 John Fordham, Deputy Director

Water Resources Center

Desert Research Institute

P.O. Box 60220

Reno, NV 89506

1 The Honorable Jim Regan

Chairman

Churchill County Board of

Commissioners

10 W. Williams Avenue

Fallon, NV 89406

1

R. R. Loux

Executive Director

Agency for Nuclear Projects

State of Nevada

Evergreen Center, Suite 252

1802 N. Carson Street

Carson City, NV 89710

1 Brad R. Mettam

Inyo County Yucca Mountain

Repository Assessment Office

P. O. Drawer I

Independence, CA 93526

1 Vernon E. Poe

Office of Nuclear Projects

Mineral County

P.O. Box 1600

Hawthorne, NV 89415 
1 Les W. Bradshaw

Program Manager

Nye County Nuclear Waste Repository

Project Office

P.O. Box 1767

Tonopah, NV 89049

1 Florindo Mariani

White Pine County Coordinator

P. O. Box 135

Ely, NV 89301

1 Tammy Manzini

Lander County Yucca Mountain Information Officer

P.O. Box 10

Austin, NV 89310

1 Jason Pitts

Lincoln County Nuclear Waste

Program Manager

P. O. Box 158

Pioche, NV 89043

1 Dennis Bechtel, Coordinator

Nuclear Waste Division

Clark County Dept. of Comprehensive Planning

P.O. Box 55171

Las Vegas, NV 89155-1751

1 Juanita D. Hoffman

Nuclear Waste Repository

Oversight Program

Esmeralda County

P.O. Box 490

Goldfield, NV 89013

1 Sandy Green

Yucca Mountain Information Office

Eureka County

P.O. Box 714

Eureka, NV 89316

1 Economic Development Dept.

City of Las Vegas

400 E. Stewart Avenue

Las Vegas, NV 89101

1 Community Planning \& Development

City of North Las Vegas

P.O. Box 4086

North Las Vegas, NV 89030

2 Librarian

YMP Research \& Study Center

101 Convention Center Drive, Suite P-110

Las Vegas, NV 89109
1

Library Acquisitions

Argonne National Laboratory

Building 203, Room CE-111

9700 S. Cass Avenue

Argonne, II 60439

1

Glenn Van Roekel

Manager, City of Caliente

P.O. Box 158

Caliente, NV 89008

1

1 Steve Hanauer (RW-2)

G. S. Bodvarsson

Head, Nuclear Waste Department

Lawrence Berkeley National Laboratory

1 Cyclotron Road, MS 50E

Berkeley, CA 94720

OCRWM

U. S. Department of Energy

1000 Independence Ave.

Washington, DC 20585

$5 \quad$ K. E. Perry, Jr.

Nike Air Lab, MJ3

1 Bowerman Drive

Beaverton, OR 97005

MS

1325

1325

1325

1325

1325

INEL

INEL

1330

N. Brodsky, 6852

L. Costin, 6852

R. Finley, 6852

E. Ryder, 6852

S. Sobolik, 6852

B. J. Buescher, Jr.

J. S. Epstein

B. Pierson, 6811

100/WBS123274/

SAND95-2182/NQ

1330 WMT Library, 6752

9018

0899

0619

Central Technical Files, 8523-2

Technical Library, 4414

Review and Approval Desk, 12630, For DOE/OSTI 